\title{
Dentistry and medicine degrees are best value for money
}

Students have rated dentistry and medicine as the degrees they consider to be the best 'value for money' out of many degree courses on offer, according to an analysis carried out by The Knowledge Academy of a recent survey.

The Academy, a UK-based global training company, analysed the latest findings ${ }^{1}$ from the Higher Education Policy Institute, which surveyed 14,046 full-time undergraduate students to

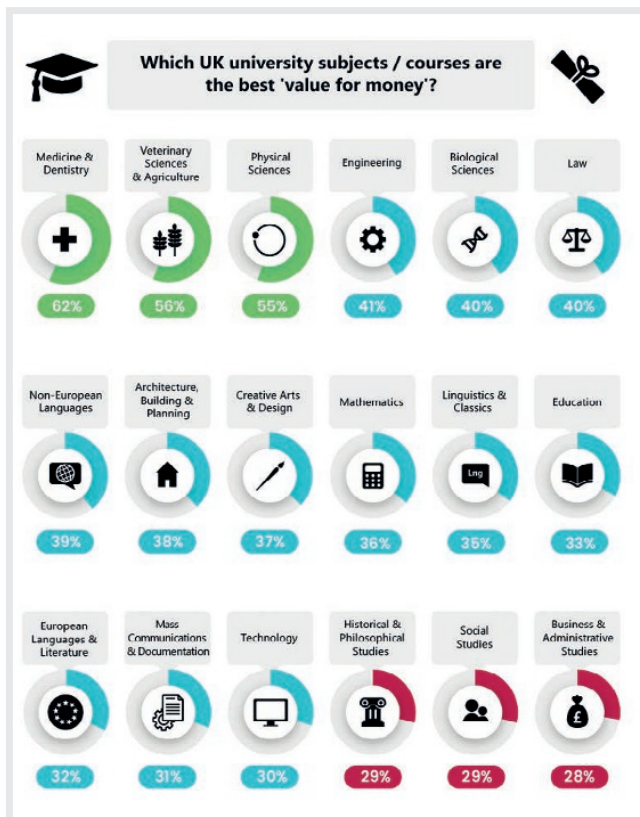
discover which university subjects/courses had the best 'value for money'.

The analysis showed that those studying medicine and dentistry (62\%) felt they were the courses which delivered the best value for money. Thereafter, students on veterinary sciences and agriculture (56\%) based degrees believed they were getting the next best return on their educational investment.

In third position, 55\% of students enrolled on a physical sciences discipline felt it offered them good value for money.

The Academy said that universities played a fundamental role in the economic and social development of the UK, and businesses and society benefited from a well-educated graduate workforce.

However, the decision by the government to allow universities to charge up to $£ 9,000$ a year in tuition fees from the academic year of 2012-13, had led many students and their parents to consider the debt they would accumulate from completing a degree at the higher tuition rates.

Joseph Scott, a Spokesperson from the TheKnowledgeAcademy. com, said: 'It's interesting to see from the point of students if their chosen university course is actually giving them value for money or not at the increased tuition fee rates.

'This research certainly shows that there are degree disciplines which are giving undergraduates who are studying them more for their money than others. But within the context of 'value', it is important to know that students tend to factor in teaching quality, course content, lecturer contact hours and availability of learning resources into their assessment.

'Rightfully so, as it paints a clearer picture of what value for money really means to them.'

1. Higher Education Policy Institute. 2018 Student Academic Experience Survey (7 June 2018). Available at https://www.hepi.ac.uk/2018/06/07/2018-student-academic-experience-survey/ (accessed 24 September 2018). 